\title{
Performance Analysis of Dispersion Compensation Fiber on NRZ and RZ Modulation with Difference Power Transmission
}

\author{
Robi Darwis*, Octarina Nur Samijayani, Ary Syahriar, Indrawan Arifianto \\ Department of Electrical Engineering, Faculty of Science and Engineering, Al Azhar University of Indonesia, Indonesia
}

Copyright $\bigcirc 2019$ by authors, all rights reserved. Authors agree that this article remains permanently open access under the terms of the Creative Commons Attribution License 4.0 International License

\begin{abstract} characteristics that really need attention. The characteristics of fiber optic transmission are very important in designing optical fiber networks, one of which is widening pulses called dispersions. Dispersion is the widening of light pulses in optical fibers which reduces data speed, signal to noise ratio and system quality. In addition to dispersion compensation, which is the most important feature needed in fiber-optic communication systems; transmission power needs to be considered to produce optimal signal output. In this paper, we will simulate the optimization effect of power and fiber dispersion compensation on Non Return to Zero (NRZ) and Return to Zero (RZ) modulation on optical transmission systems, with $5 \mathrm{dBm}$ power parameters, $10 \mathrm{dBm} 15 \mathrm{dBm}$ and $0 \mathrm{dBm}$ and DCF $5 \mathrm{~km}, 10 \mathrm{~km}, 15 \mathrm{~km}, 20 \mathrm{~km}$ and $25 \mathrm{~km}$. Simulation results show that dispersion compensation is very influential on the transmission system. From these two modulations, there are differences in the results between NRZ and RZ. The results of dispersion compensation also affect the input power and DCF length.
\end{abstract}

Keywords DCF, Power Transmission, NRZ, RZ

\section{Introduction}

The characteristics of fiber optic transmission are very important in designing fiber optic networks [1,2]. Optical communication systems also face problems such as dispersion (chromatic dispersion, polarization dispersion modes, second order and third order dispersion), attenuation and nonlinear effects that limit performance. Dispersion factors are a very dominant problem compared to others [3, 4].

Effectively dispersion speaks of widening pulses. Dispersion is the effect that is responsible for spreading the signal when propagating. The signal is represented by pulses [5]. Dispersion is the widening of light pulses in optical fibers which reduces data speed, signal ratio to noise and system quality. The widening of this pulse leads to Inter-Symbol-Interference (ISI), where the output pulses of a system will experience interference or overlap, so the output becomes undetectable [4].

Besides dispersion compensation, which is the most important feature needed in a fiber optic communication system[6], it seems that the best solution for high attenuation is to pump more optical power or concentrate and focus on power optimization. External modulation is usually adopted. In terms of power efficiency and bandwidth efficiency, a number of the most popular modulation techniques are used [7].

Modulation techniques that are widely used in optical communication systems are generally simple modulation-based on-off keying (OOK)[8]. This paper will analyze the performance of optical systems using dispersion compensation fiber and power optimization for NRZ and RZ modulation techniques. Performance will be analyzed based on measurements of Q factor, Bit Error Rate (BER) and Eye Diagram by varying various parameters and optimize the launch power and DCF length to maximize the good quality transmissions.

\section{Basic Theory}

\subsection{Dispersion}

Dispersion is the most significant factor affecting performance as a transmission medium. The pulse widening level is very sensitive to the exact match of the zero dispersion wavelength and the center wavelength. The pulse width received is directly related to the transmission data rate in bits per second. For single silica-based fuser modes designed for dispersion shifts, the dominant effect 
on the design comes from the waveguide component of total dispersion. This is the only component that can be changed significantly by the appropriate modification of the refractive index profile shape [9].

Attenuation and dispersion are the two most important effects that play a major role in fiber optic transmission systems. Attenuation of optical signals will limit the availability of optical power along the transmission path, and for very low attenuation, the dispersion limit of the repeater distance is below what is possible from attenuation factors. Fat loss has been reduced from $100 \mathrm{~dB} / \mathrm{km}$ (i.e., transmission may be only a few meters) at $1,300 \mathrm{~nm}$ in 1970 to around 025 and $015 \mathrm{~dB} / \mathrm{km}$ which is very close to transparent boundaries which may be theoretically and transmission over several hundred kilometers fiber, for the wavelength region of 1300 and $1550 \mathrm{~nm}$ respectively, in 1980 [9].

\subsection{The Effect of Fiber Optic Dispersion on Optical Transmission}

Loss and dispersion are the major factor that affect fiber-optical communication being the high-capacity develops. The EDFA is the gigantic change happened in the fiber-optical communication system; the loss is no longer the major factor to restrict the fiber-optical transmission. Since EDFA works in $1550 \mathrm{~nm}$ wave band, the average Single Mode Fiber (SMF) dispersion value in that wave band is very big, about 15-20ps / ( nm. km-1). It is easy to see that the dispersion becomes the major factors that restrict long distance fiber-optical transfers $[3,10,11]$.

In single-mode fiber, performance is primarily limited by chromatic dispersion which occurs because the index of the glass varies slightly depending on the wavelength of the light, as the light from real optical transmitter necessarily has nonzero spectral width. Polarization mode dispersion, another source of limitation occurs because although the single-mode fiber can sustain only one transverse mode, it can be carried with two different polarizations, and slight imperfections or distortions in a fiber can alter the propagation velocities for these two polarizations [3], [10], [11]. This phenomenon is called polarization mode dispersion and Mode birefringence $\mathrm{Bm}$ is defined as the follow

$$
\mathrm{Bm}=\frac{\left|\beta_{\mathrm{x}}-\beta_{\mathrm{y}}\right|}{\mathrm{k}_{0}}=\mathrm{n}_{\mathrm{x}}-\mathrm{n}_{\mathrm{y}}
$$

$\mathrm{n}_{\mathrm{x}}, \mathrm{n}_{\mathrm{y}}$ are the effective refractive of the two orthogonl polarizations. For a given $\mathrm{Bm}$, its fast axis and slow axis components would develop the phase difference after the light waves transmission $\mathrm{L} \mathrm{Km}$.

$$
\Phi=\mathrm{k}_{0} B m \mathrm{~L}=\frac{2 \pi}{\lambda}\left(\mathrm{N}_{\mathrm{x}}-\mathrm{N}_{\mathrm{y}}\right) \mathrm{L}=\left(\beta_{\mathrm{x}}-\beta_{\mathrm{y}}\right) \mathrm{L}
$$

If the $\mathrm{Bm}$ remains constant, the phase difference between its fast axis and slow axis will be periodically repeated. The length that leads to a phase difference of $2 \pi$ or power periodic exchange is called polarization beat length:

$$
\mathrm{L}=\frac{2 \pi}{\left|\beta_{\mathrm{x}}-\beta_{\mathrm{y}}\right|}=\frac{\lambda}{\mathrm{Bm}}
$$

If the incident light has two polaization components, due to refactive difference between the fast axis and slow axis, the tansmit rate of two polaization components will be different. Because the randomness of fiber birefingence changes, the group velocity of different polaization direction is also random, and this will result in the outut pulse broadening. Degee of pulse broadening can be expressed by different group delay $\Delta \mathrm{T}$.

$$
\Delta \tau=\left|\frac{\mathrm{L}}{\mathrm{V}_{\mathrm{gx}}}-\frac{\mathrm{L}}{\mathrm{V}_{\mathrm{gy}}}\right|=\frac{\mathrm{d}}{\mathrm{d} \omega}\left(\beta_{\mathrm{x}}-\beta_{\mathrm{y}}\right) \mathrm{L}=\left(\frac{\mathrm{n}_{\mathrm{x}}-\mathrm{n}_{\mathrm{y}}}{\mathrm{c}}+\frac{\omega}{\mathrm{c}} \frac{\mathrm{d}\left(\mathrm{n}_{\mathrm{x}}-\mathrm{n}_{\mathrm{y}}\right)}{\mathrm{dc}}\right) \mathrm{L}
$$

From the equations present that the initial pulse is broadened by the transmission. The longer the optical signal transmission distance, the geater the fiber dispersion coefcient, the more pulse broaden. The two adjacent pulses result overheating, error judgment will generated $[10,11]$.

The influence of dispersion on system performance is also reflected in the optical fiber nonlinear effects. Dispersion increased the pulse shape distortion caused by the self-phase modulation dispersion (SPM); on the other hand, dispersion in WDM systems can also increase the cross-phase modulation, four-wave mixing (FWM) and other nonlinear effects [10-12].

\subsection{DCF Dispersion Compensation Technology}

In order to improve overall system performance and reduced as much as possible the transmission performance influenced by the dispersion, several dispersion compensation technologies were proposed [6]. Amongst the various techniques proposed in the literature, the ones that appear to hold immediate promise for dispersion compensation and management could be broadly classified as: dispersion compensating fibers (DCF), chirped fiber Bragg gratings (FBG) and high-order mode (HOM) fiber [10], [13].

The idea of using dispersion compensation fiber for dispersion compensation was proposed as early as in 1980, but it was not until the invention of optical amplifiers that DCF began to receive attention and be studied. As products of DCF are more mature, stable, not easily affected by temperature and wide bandwidth, DCF has become a most useful method of dispersion compensation [13].

There is positive second-order and third-order dispersion value in SMF (single mode fiber), while the DCF dispersion value is negative. So by inserting a DCF, the average dispersion is close to zero [11]. As the local dispersion of higher transmission link, FWM and XPM were ignored; only to consider the role of SPM and dispersion, the signal transmission can be simulate by solve the nonlinear Schrodinger equation: 


$$
\frac{\partial A_{j}(z, t)}{\partial z}+\frac{1}{2} i \beta_{2}\left(\lambda_{j}\right) \frac{\partial^{2} A_{j}(z, t)}{\partial t^{2}}-i \gamma\left|A_{j}(z, t)\right|^{2} A_{j}(z, t)+\frac{\alpha}{22} A_{j}(z, t)=0
$$

$\mathrm{A}_{\mathrm{j}}(\mathrm{z}, \mathrm{t})$ is complex amplitude of $\mathrm{j}$ channel optical pulse, $\beta_{2}\left(\lambda_{\mathrm{i}}\right)$ is the dispersion parameter of $\mathrm{j}$ channel, $\gamma$ is the nonlinear co-efficent, $\alpha$ is the loss co-efficient. After N-section dispersion compensation of DCF, the channel residual dispersion can be expressed as:

$$
\Delta \mathrm{D}\left(\lambda_{\mathrm{j}}\right)=\mathrm{NL}_{\mathrm{SMF}}\left(\left(1-\mu_{\mathrm{p}}\right) \mathrm{D}_{\mathrm{SMF}}\left(\lambda_{\mathrm{p}}\right)+(\mathrm{j}-\mathrm{p}) \Delta \lambda\left(\frac{\mathrm{dD}_{\mathrm{SMF}}\left(\lambda_{\mathrm{p}}\right)}{\mathrm{d} \lambda}-\frac{\mu_{\mathrm{p}} \mathrm{D}_{\mathrm{SMF}}\left(\lambda_{\mathrm{p}}\right)}{\mathrm{D}_{\mathrm{DCF}}\left(\lambda_{\mathrm{p}}\right)} \frac{\mathrm{dD}_{\mathrm{SMF}}\left(\lambda_{\mathrm{p}}\right)}{\mathrm{d} \lambda}\right)\right)
$$

In the formula, $\mu p$ is the dispersion compensation rate of p-channel.

$$
\mu_{\mathrm{p}}=\left|\frac{\mathrm{D}_{\mathrm{DCF}}\left(\lambda_{\mathrm{p}}\right) \mathrm{L}_{\mathrm{DCF}}}{\mathrm{D}_{\mathrm{SMF}}\left(\lambda_{\mathrm{p}}\right) \mathrm{L}_{\mathrm{SMF}}}\right|
$$

$\mathrm{L}_{\mathrm{SMF}}$ and $\mathrm{L}_{\mathrm{DCF}}$ are the conventional single-mode fiber length and dispersion compensation fiber length within the amplifer spacing. $\Delta \lambda$ is the channel wavelength spacing. $\mathrm{D}_{\mathrm{DCF}}\left(\lambda_{\mathrm{p}}\right)$ and $\mathrm{D}_{\mathrm{SMF}}\left(\lambda_{\mathrm{p}}\right)$ ae the dispersion coefcient of conventional single-mode fiber and dispersion compensation fber at the $\lambda_{\mathrm{p}}$ wavelength[10, 11].

\subsection{Modulation Technique}

When analyzing the performance of optical communication systems, the data transmission format must be analyzed because it deals directly with the system output. Many coding techniques have been proposed before and have become standard in telecommunication and computer networks [14]. Optical modulation format is a method used to impress data on optical carrier waves for transmission through optical fibers. The simplest optical modulation format is modulation of on-off-keying (OOK) intensity, which can consist of two forms: non-return-to-zero (NRZ) and return-to zero (RZ) [15]. Return to zero (RZ) and non-return to zero (NRZ) are two very common modulation techniques, which are used to modulate optical pulses in optical networks. In a simple comparison, the NRZ modulation technique requires less bandwidth for transmission than RZ and is not sensitive to laser phase noise [16].

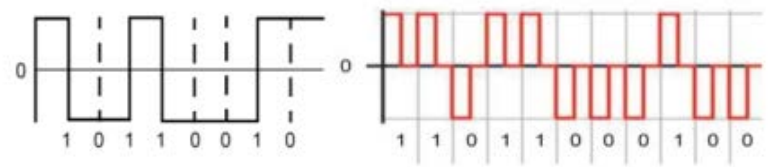

(a)

(b)

Figure 1. (a) NRZ and (b) RZ of Optical Communication [17]

Each of these modulation schemes offers a certain optical average power, and therefore they are usually compared in terms of the average optical power required to achieve a desired BER performance or SNR. The power effciency $\eta p$ of a modulation scheme is given by the average power required to achieve a given BER at a given data rate [7]. Mathematically, $\eta p$ is defined as:

$$
\eta_{\mathrm{p}}=\frac{E_{\text {pulse }}}{E_{b}}
$$

where $E_{\text {pulse }}$ is the energy per pulse and $E_{b}$ is the average energy per bit.

\section{Methodology}

In this paper, we investigate the effect of the length of dispersion compensation fiber (DCF) and the optimization of power launch on the data transmission system. This study designed a simulation using two modulation techniques namely NRZ and RZ. This simulation uses Optisystem 7.0.

The following parameters are set in this study:

Table 1. Standard Single-Mode Fiber Parameters

\begin{tabular}{ll}
\hline Parameters & Values \\
\hline Reference Wavelength & $1550 \mathrm{~nm}$ \\
\hline Length of Fiber & $10 \mathrm{~km}$ \\
\hline Attenuasi & $0.2 \mathrm{~dB} / \mathrm{km}$ \\
\hline Dispersion & $16.75 \mathrm{ps} / \mathrm{nm} / \mathrm{km}$ \\
\hline Dispersi slope & $0.075 \mathrm{ps} / \mathrm{nm}^{2} / \mathrm{km}$ \\
\hline Differential Group Delay & $0.2 \mathrm{ps} / \mathrm{km}$ \\
\hline Lower calculation limit & $1200 \mathrm{~nm}$ \\
\hline Upper calculation limit & $1700 \mathrm{~nm}$ \\
\hline Power Transmitter & $5 \mathrm{dBm}, 10 \mathrm{dBm}, 15 \mathrm{dBm}, 20 \mathrm{dBm}$ \\
\hline
\end{tabular}

This single-mode fiber can cause attenuation and dispersion in fiber transmission data. Therefore, the transmission media also requires amplifiers and DCF (Dispersion Compensating Fiber).

Table 2. Dispersion Compensating Fiber Parameters

\begin{tabular}{ll}
\hline Parameters & Values \\
\hline Attenuasi & $0.2 \mathrm{~dB} / \mathrm{km}$ \\
\hline Dispersion & $-85 \mathrm{ps} / \mathrm{nm} / \mathrm{km}$ \\
\hline Dispersi slope & $-0.3 \mathrm{ps} / \mathrm{nm}^{2} / \mathrm{km}$ \\
\hline Differential Group Delay & $0.2 \mathrm{ps} / \mathrm{km}$ \\
\hline Lower calculation limit & $1400 \mathrm{~nm}$ \\
\hline Upper calculation limit & $1700 \mathrm{~nm}$ \\
\hline Length of DCF & $5 \mathrm{~km}, 10 \mathrm{~km}, 15 \mathrm{~km}, 20 \mathrm{~km}, 25 \mathrm{~km}$ \\
\hline
\end{tabular}


The output of the transmission media will then be input for optical receivers.

For the above parameters, it will be analyzed how the effect of changing each power on each length of Dispersion Compensating Fiber in both RZ and NRZ modulation.

\section{Result and Analysis}

\subsection{Results of Power Receiver in Difference Input Power and DCF Length}

The table below is the result of a simulation of the effect of input power on different DCF lengths and on different modulation techniques on NRZ and RZ.

Figure 1 shows a comparison of the power receiver to distance. The graph above is how the DCF length affects the power receiver results. It is seen that the greater the DCF distance, the smaller the power receiver.

Table 3. Power receiver results from simulations with difference power input in difference distance

\begin{tabular}{|c|c|c|c|}
\hline $\begin{array}{l}\text { Input } \\
\text { Power }\end{array}$ & $\begin{array}{l}\text { Length of DCF } \\
(\mathrm{km})\end{array}$ & NRZ & $\mathrm{RZ}$ \\
\hline \multirow{5}{*}{$5 \mathrm{dBm}$} & 5 & $-1.097 \mathrm{dBm}$ & $-4.012 \mathrm{dBm}$ \\
\hline & 10 & $-2.097 \mathrm{dBm}$ & $-5.012 \mathrm{dBm}$ \\
\hline & 15 & $-3.097 \mathrm{dBm}$ & $-6.011 \mathrm{dbm}$ \\
\hline & 20 & $-4.097 \mathrm{dBm}$ & $-7.011 \mathrm{dBm}$ \\
\hline & 25 & $-5.097 \mathrm{dBm}$ & $-8.012 \mathrm{dBm}$ \\
\hline \multirow{5}{*}{$10 \mathrm{dBm}$} & 5 & $3.990 \mathrm{dBm}$ & $0.986 \mathrm{dBm}$ \\
\hline & 10 & $2.990 \mathrm{dBm}$ & $-0.012 \mathrm{dBm}$ \\
\hline & 15 & $1.990 \mathrm{dBm}$ & $-1.012 \mathrm{dBm}$ \\
\hline & 20 & $0.990 \mathrm{dBm}$ & $-2.012 \mathrm{dBm}$ \\
\hline & 25 & $-0.010 \mathrm{dBm}$ & $-3.012 \mathrm{dBm}$ \\
\hline \multirow{5}{*}{$15 \mathrm{dBm}$} & 5 & $8.990 \mathrm{dBm}$ & $5.916 \mathrm{dBm}$ \\
\hline & 10 & $7.990 \mathrm{dBm}$ & $4.916 \mathrm{dBm}$ \\
\hline & 15 & $6.990 \mathrm{dBm}$ & $3.915 \mathrm{dBm}$ \\
\hline & 20 & $5.990 \mathrm{dBm}$ & $2.916 \mathrm{dBm}$ \\
\hline & 25 & $4.990 \mathrm{dBm}$ & $1.916 \mathrm{dBm}$ \\
\hline \multirow{5}{*}{$20 \mathrm{dBm}$} & 5 & $13.903 \mathrm{dBm}$ & $10.916 \mathrm{dBm}$ \\
\hline & 10 & $12.903 \mathrm{dBm}$ & $9.916 \mathrm{dBm}$ \\
\hline & 15 & $11.903 \mathrm{dBm}$ & $8.916 \mathrm{dBm}$ \\
\hline & 20 & $10.903 \mathrm{dBm}$ & $7.915 \mathrm{dBm}$ \\
\hline & 25 & $9.903 \mathrm{dBm}$ & $6.915 \mathrm{dBm}$ \\
\hline
\end{tabular}

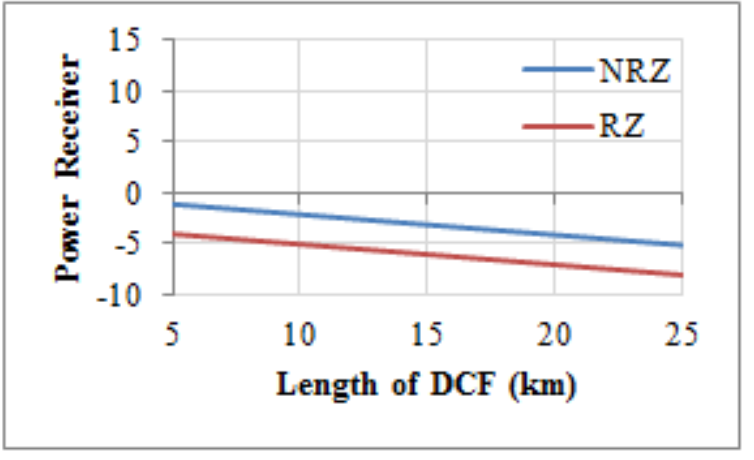

(a) power input $5 \mathrm{dBm}$

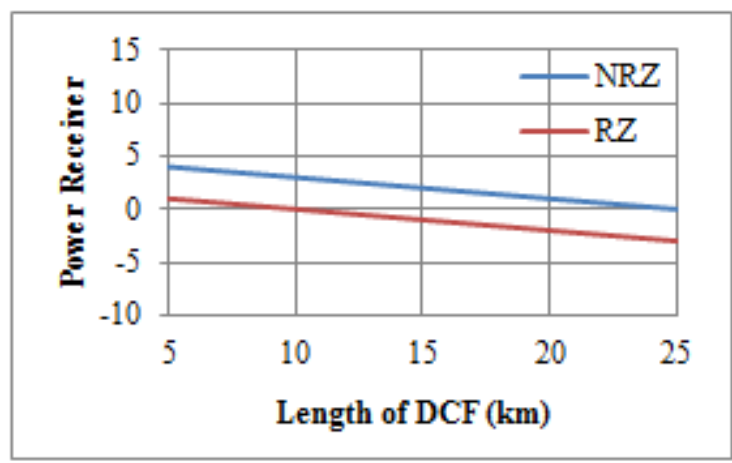

(b) power input $10 \mathrm{dBm}$

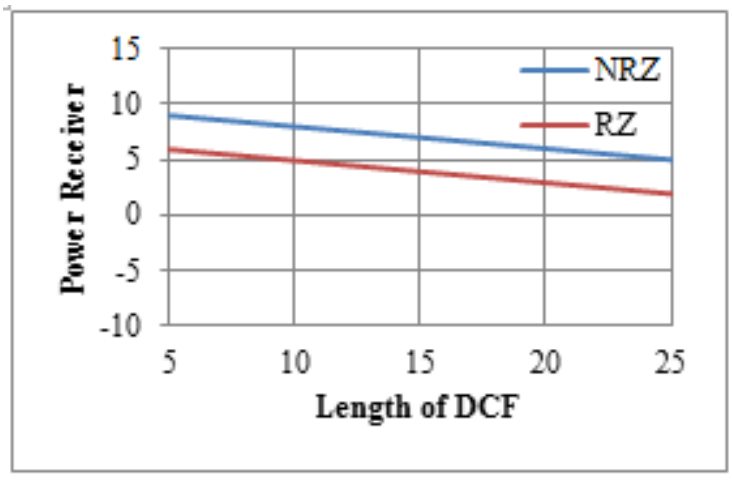

(c) power input $15 \mathrm{dBm}$

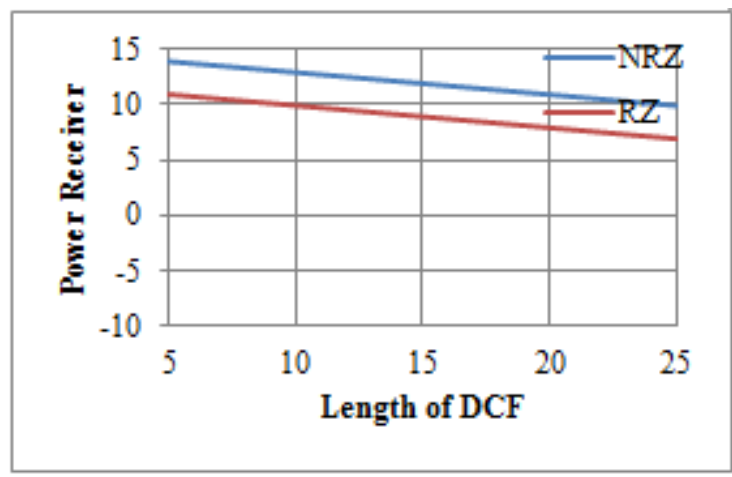

(d) power input $20 \mathrm{dBm}$.

Figure 1. Graph of Power Receiver to Length of DCF in NRZ and RZ 


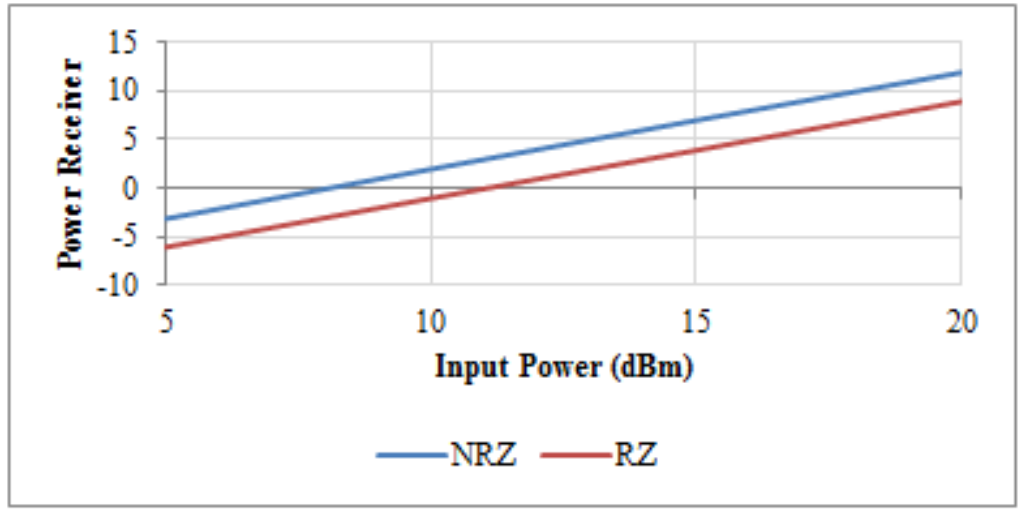

Figure 2. Graph of Power Receiver to Input power

Figure 2 shows how the power input added to the power receiver on this DCF system. From the graph above, it can be seen that the greater the input power, the more powerful the power receiver.

\subsection{Q Factor and Bit Error Rate Analysis}

The following table is the result of a power optimization and dispersion compensation simulation on NRZ modulation with variations in the power delivery to each DCF length variation. This simulation produces the number of Q Factor and Bit Error Rate (BER)

Table 4. Q G Factor and BER results from simulations using NRZ modulation

\begin{tabular}{ccccccc}
\hline Power & & $\mathbf{5} \mathbf{~ k m}$ & $\mathbf{1 0} \mathbf{~ k m}$ & $\mathbf{1 5} \mathbf{~ k m}$ & $\mathbf{2 0} \mathbf{~ k m}$ & $\mathbf{2 5} \mathbf{~ k m}$ \\
\hline \multirow{2}{*}{$5 \mathrm{dBm}$} & Q Factor & 24.3869 & 12.2258 & 7.58777 & 4.51183 & 2.48181 \\
& BER & $1.12 \mathrm{e}-131$ & $1.12 \mathrm{e}-034$ & $1.62 \mathrm{e}-014$ & $3.21 \mathrm{e}-006$ & 0.00649 \\
\hline \multirow{2}{*}{$10 \mathrm{dBm}$} & Q Factor & 24.3628 & 12.8714 & 6.96144 & 4.23604 & 2.32612 \\
& BER & $1.95 \mathrm{e}-131$ & $3.261 \mathrm{e}-038$ & $1.68 \mathrm{e}-012$ & $1.135 \mathrm{e}-005$ & 0.009945 \\
\hline \multirow{2}{*}{$15 \mathrm{dBm}$} & Q Factor & 25.7458 & 15.3727 & 5.35276 & 3.44015 & 1.93778 \\
& BER & $1.67 \mathrm{e}-146$ & $1.136 \mathrm{e}-053$ & $4.33 \mathrm{e}-008$ & 0.0002895 & 0.026226 \\
\hline \multirow{2}{*}{$20 \mathrm{dBm}$} & Q Factor & 11.809 & 6.84841 & 2.70905 & 1.90257 & 0 \\
& BER & $1.68 \mathrm{e}-032$ & $3.7224 \mathrm{e}-012$ & 0.00335531 & 0.0284968 & 1 \\
\hline
\end{tabular}

From the table above, it can be seen that the type of power launched at different levels produces different $\mathrm{Q}$ Factors and BER at each distance or length of the DCF.

Table 5. Q Factor and BER results from simulations using RZ modulation

\begin{tabular}{ccccccc}
\hline Power & & $\mathbf{5 ~ k m}$ & $\mathbf{1 0} \mathbf{~ k m}$ & $\mathbf{1 5} \mathbf{~ k m}$ & $\mathbf{2 0} \mathbf{~ k m}$ & $\mathbf{2 5} \mathbf{~ k m}$ \\
\hline \multirow{2}{*}{$5 \mathrm{dBm}$} & Q Factor & 46.3815 & 19.5877 & 2.5202 & 0 & 0 \\
& BER & 0 & $9.417 \mathrm{e}-086$ & 0.00480306 & 1 & 1 \\
\hline \multirow{2}{*}{$10 \mathrm{dBm}$} & Q Factor & 41.7241 & 17.6244 & 2.31997 & 0 & 0 \\
& BER & 0 & $7.8161 \mathrm{e}-070$ & 0.00865602 & 1 & 1 \\
\hline \multirow{2}{*}{$15 \mathrm{dBm}$} & Q Factor & 29.2253 & 11.9276 & 1.81269 & 0 & 0 \\
& BER & $4.61 \mathrm{e}-188$ & $4.2426 \mathrm{e}-033$ & 0.0318803 & 1 & 1 \\
\hline \multirow{2}{*}{$20 \mathrm{dBm}$} & Q Factor & 7.27353 & 3.7132 & 0 & 0 & 0 \\
& BER & $1.74 \mathrm{e}-013$ & $9.3166 \mathrm{e}-005$ & 1 & 1 & 1 \\
\hline
\end{tabular}

The above table is the result of power optimization simulation and dispersion compensation at RZ modulation with variations in the delivery power of each variation of DCF length. This simulation produces the number of Q Factor and Bit Error Rate (BER). It can be seen more clearly through the picture below. 

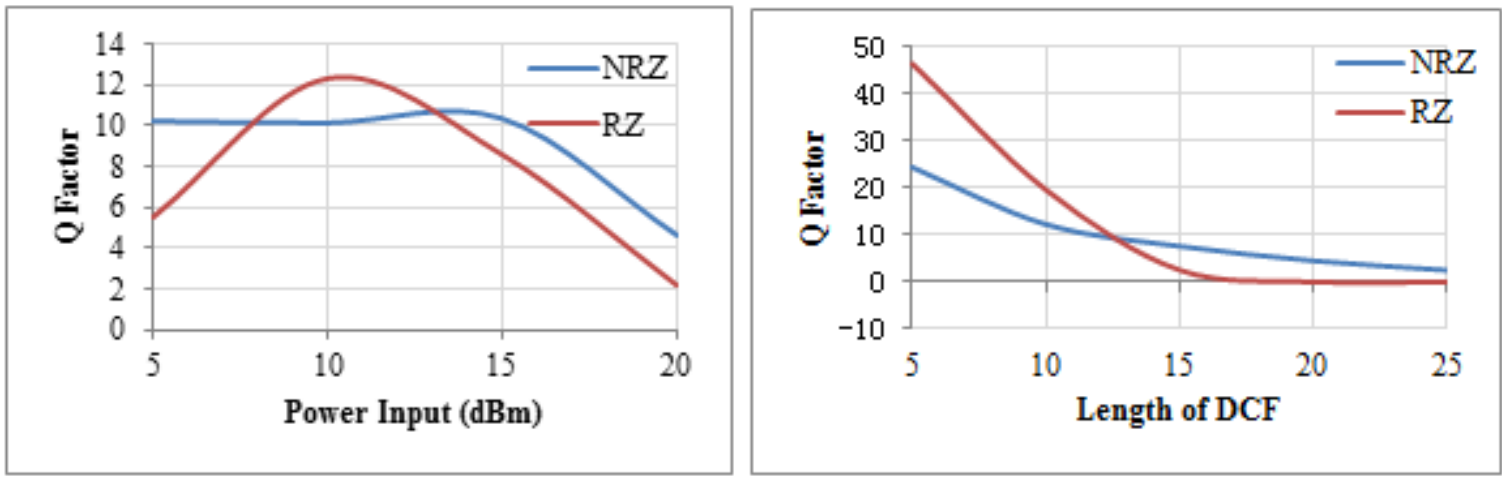

Figure 3. Comparison of $\mathrm{Q}$ factor to input power and to DCF length

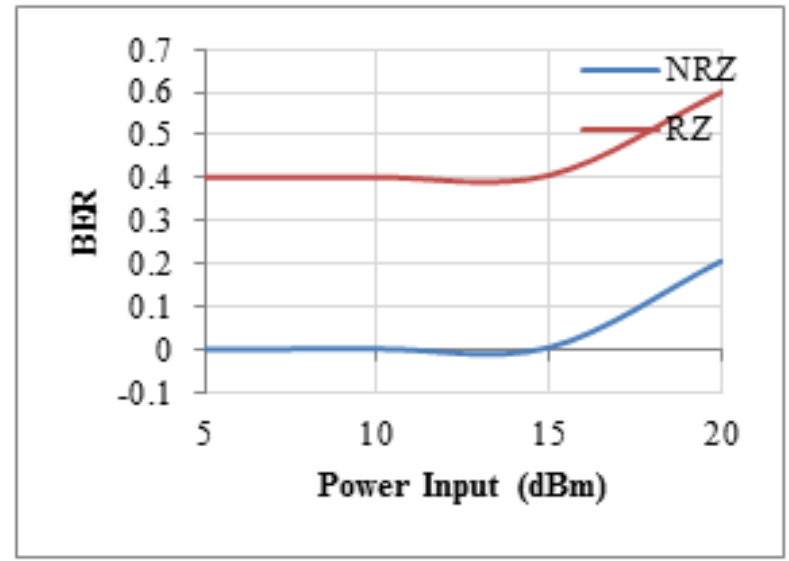

Figure 4. Comparison of BER to input power

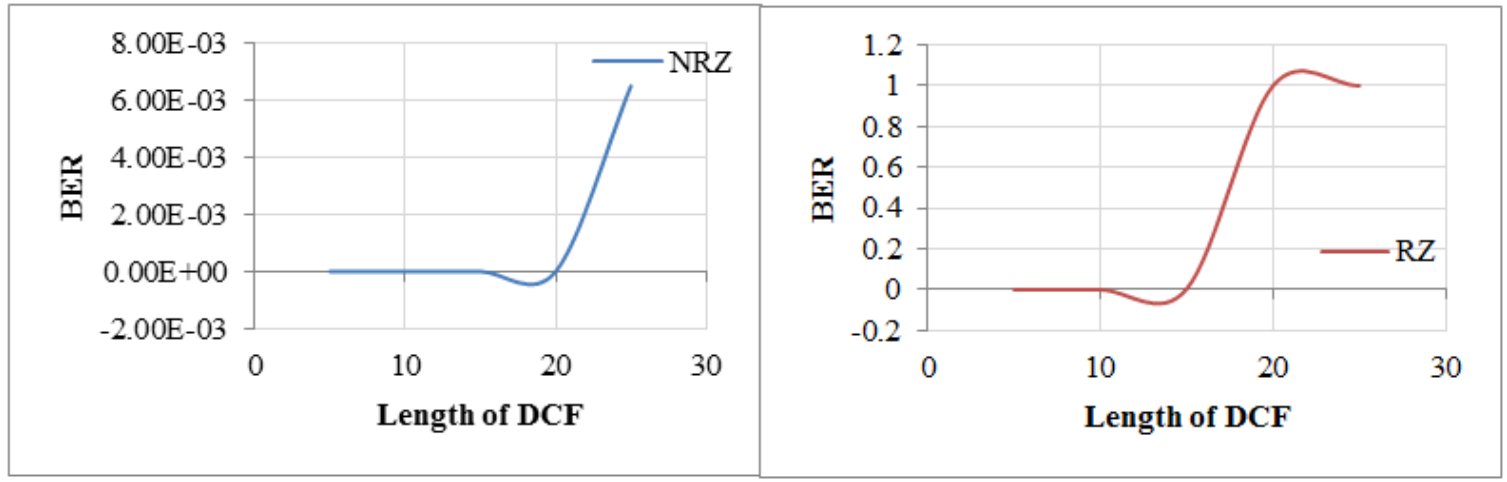

Figure 5. Comparison of BER on DCF length

From table 4 and table 5, it can be analyzed that each addition of Dispersion compensating fiber will decrease the Q Factor value. The decrease in the Q Factor is due to one of the optical fiber dispersion values that accumulate when the link is getting farther away, where the positive dispersion value possessed by the SMF optical fiber accumulates positively linearly as the link length increases. The greater the accumulation of the dispersion value, the smaller delay between channels, which gives rise to a significant Inter Symbol Interference (ISI). The use of DCF optical fiber which has negative dispersion value can reduce the positive dispersion value of SMF, where it accumulates positively linearly with increasing link length, thus increasing delay between channels that significantly reduce Inter Symbol Interference (ISI).

Then when the input power is large, the system will reach a high BER value. If the BER value reaches the lowest point, the system has optimal performance. This lowest point is a reference to determine the best input power value. Given that high-speed fiber optic communication systems and long transmission transmissions require large input power, if a system can be given more power with good transmission quality, the system is said to be a good system. 


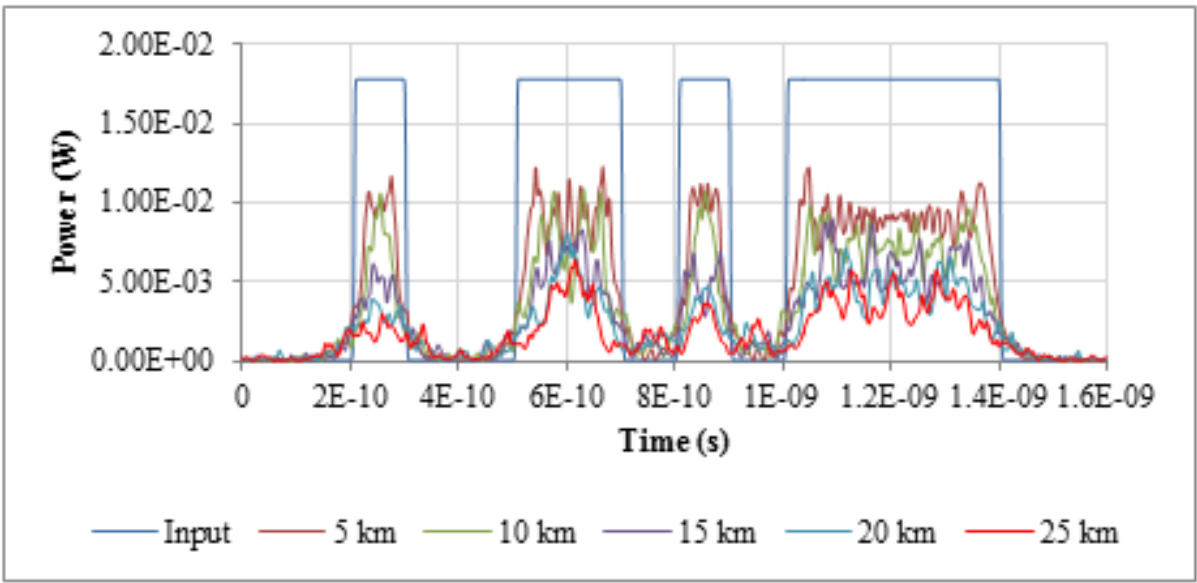

Figure 6. Graph of input and output with the difference of DCF length in NRZ

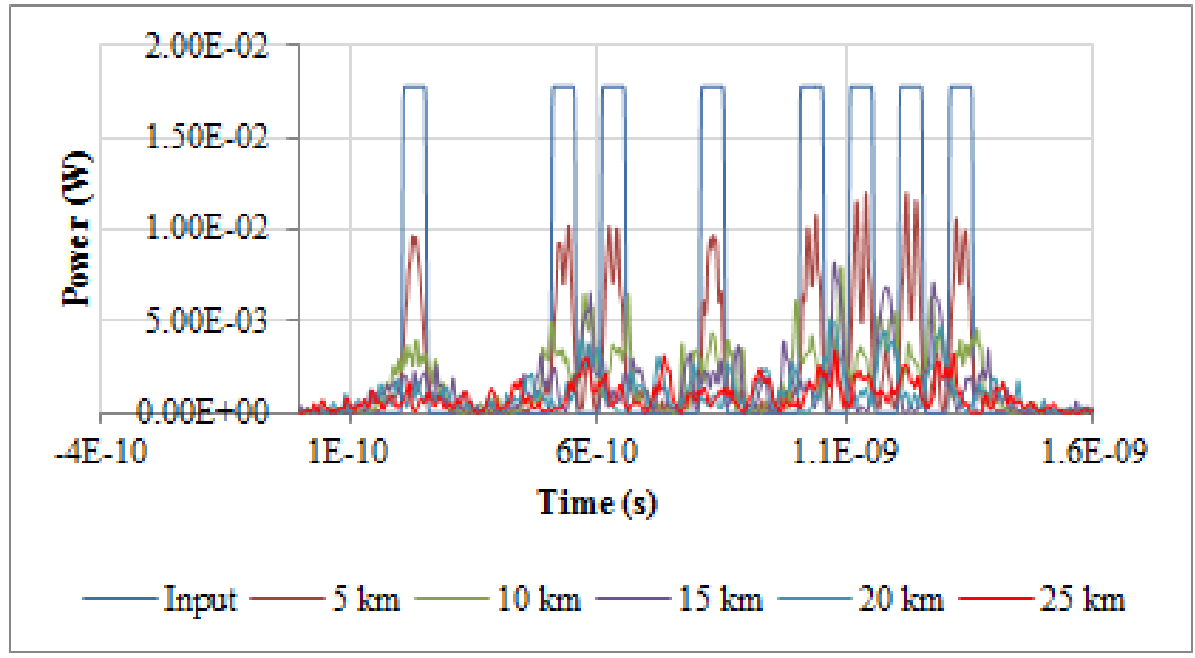

Figure 7. Graph of input and output with the difference of DCF length in RZ

\subsection{Input and Output Analysis}

Below is a graph of the input and output comparisons for each different distance. In this simulation, the input power entered is the average power of the previous test, which is $12.5 \mathrm{dBm}$ with a variable length DCF variable that varies from $5 \mathrm{~km}$ to $25 \mathrm{~km}$ in multiples of 5 .

Figure 6 and 7 show a comparison of the input signal and output signal in each modulation. Figure 6 shows a graph of the input and output signals on the NRZ transmission and figure 7 shows a graph of the input signal and output signal on the RZ transmission. It was seen that both experienced noise did not get a full signal on the receiver. This happens because of the effects of dispersion and noise during propagation.

\section{Conclusions}

Based on the above analysis, it can be concluded that by using power transmitter optimization and dispersion compensation on optical transmission systems greatly affects system performance. The bigger the transmitter power, the $\mathrm{Q}$ factor will decrease and the BER will increase. As well as the addition of DCF, the $\mathrm{Q}$ factor will decrease and the BER will increase. Therefore power optimization and dispersion compensation fiber greatly influence the performance of the optical transmission system. Based on the replacement of the modulation technique used between Non Return to Zero (NRZ) and Return to Zero (RZ), in testing different input power NRZ produces a small Bit Error Rate than NR. In testing by varying the length of DCF even the value of BER on NRZ is smaller than RZ. These results can be concluded that NRZ is better than NZ when viewed in terms of BER.

\section{Appendix}

\section{Bit Error Rate}

Assuming Gaussian noise with the standard deviations $\sigma_{0}$ and $\sigma_{1}$, the BER is [17]: 


$$
\mathrm{P}_{\mathrm{e}}=\frac{\mathrm{M}}{\mathrm{N}+\mathrm{M}} \mathrm{Pe} 1+\frac{\mathrm{N}}{\mathrm{M}+\mathrm{N}} \mathrm{Pe}_{1}
$$

where $\mathrm{P}_{0}$ and $\mathrm{P}_{1}$ are the probabilities of the symbols, $\mathrm{M}$ is the number of samples for the logical 0 , and $\mathrm{N}$ is the number of samples for the logical 1 . Also, $\mathrm{P}_{\mathrm{e}} 0$ and $\mathrm{P}_{\mathrm{e}} 1$ are:

$$
\begin{gathered}
\mathrm{P}_{\mathrm{e} 0}=\frac{1}{2} \operatorname{erfc}\left(\frac{\mathrm{S}-\mu 0}{\sqrt{2 \sigma 0}}\right) \\
\mathrm{P}_{\mathrm{e} 1}=\frac{1}{2} \operatorname{erfc}\left(\frac{\mu 1-\mathrm{S}}{\sqrt{2 \sigma 1}}\right)
\end{gathered}
$$

Where $\mu_{0}, \mu_{1}, \sigma_{0}$ and $\sigma_{1}$ are average values and standard deviations of the sampled values respectively, and $\mathrm{S}$ is the threshold value.

An enhancement of the simple Gaussian approximation can be achieved by averaging the separately estimated BERs for different sampled symbols [9]. For $\mathrm{M}$ sampled values for the logical 0 and $\mathrm{N}$ sampled values for the logical 1 , the corresponding error rates are:

$$
\begin{aligned}
& \mathrm{P}_{\mathrm{e} 1}=\frac{1}{2 \mathrm{~N}} \sum_{\mathrm{i}=1}^{\mathrm{N}} \operatorname{erfc}\left(\frac{\mu_{1} \mathrm{i}-\mathrm{S}}{\sqrt{2 \sigma 1 \mathrm{i}}}\right) \\
& \mathrm{P}_{\mathrm{e} 0}=\frac{1}{2 \mathrm{M}} \sum_{\mathrm{i}=1}^{\mathrm{M}} \operatorname{erfc}\left(\frac{\mu_{0} \mathrm{i}-\mathrm{S}}{\sqrt{2 \sigma 0 \mathrm{i}}}\right)
\end{aligned}
$$

If the signal is mixed with the noise, the Average Gaussian method is modified to calculate the average error patterns. The detailed description is [14]:

$$
\mathrm{P}_{\mathrm{e}}=\sum_{\mathrm{i}=1}^{8} \frac{\mathrm{NP}}{\mathrm{M}} \operatorname{erfc}\left(\frac{\mu_{i}-\mathrm{S}}{\sqrt{2 \sigma \mathrm{i}}}\right)
$$

\section{Q Factor}

There are two modes to calculate the Q-Factor:

The Q-Factor from BER is calculated numerically by:

$$
\mathrm{P}_{\mathrm{e}}=\frac{1}{2} \operatorname{erfc}\left(\frac{\mathrm{Q}}{\sqrt{2}}\right)
$$

where the Q-Factor is calculated:

$$
\mathrm{Q}=\frac{\left|\mu_{1}-\mu_{0}\right|}{\sigma_{1}-\sigma_{0}}
$$

\section{REFERENCES}

[1] K. Iizuka, Elements of Photonics For Fiber Integrated Optics, 2nd ed. New York: Wiley Interscience, 2002.

[2] G. Singh and J. Saxena, "Dispersion Compensation Using FBG and DCF in 120 Gbps WDM System,” Int. J. Eng. Sci. Innov. Technol., vol. 3, no. 6, pp. 514-519, 2014.

[3] M. Yadav and A. K. Jaiswal, "Design Performance of High Speed Optical Fiber WDM System with Optimally Placed DCF for Dispersion Compensation,” Int. J. Comput. Appl., vol. 122, no. 20, pp. 36-39, 2015.

[4] V. Joshi and R. Mehra, "Performance Analysis of an Optical System Using Dispersion Compensation Fiber \& Linearly Chirped Apodized Fiber Bragg," Open Phys. J., pp. 114121, 2016.
[5] M. S. Wartak, Computational Photonics An Introduction with MATLAB. New York: Cambridge University Press, 2013.

[6] R. Udayakumar, V. Khanaa, and T. Saravanan, "Chromatic Dispersion Compensation in Optical Fiber Communication System and its Simulation,” ndian J. Sci. Technol., vol. 6, pp. 1-5, 2013.

[7] R. Ghassemloy, Z; W, Popoola; S, Optical Wireless Communications System and Channel Modelling with MATLAB. Londo: CRC Press Taylor And Francis Group, 2013.

[8] D. Astharini, A. Mayola, O. N. Samijayani, and A. Syahriar, "Performance Analysis of Digital Modulation Techniques on Wireless Optical Channel,” vol. 17, no. 1, pp. 7-12, 2017.

[9] B. H, Le, and Nguyen, Guided Wave Photonics Fundamentals and Application With MATLAB. Australia: CRC Press Taylor And Francis Group, 2012.

[10] B. Hu, W. Jing, W. Wei, and R. Zhao, "Analysis on Dispersion Compensation with DCF based on Optisystem," Int. Conf. Ind. Inf. Syst., vol. 6, no. 8, pp. 40-43, 2010.

[11] A. B. Sarkar and K. S. Alam, "Analysis of Dispersion Compensation System for Optical Fiber Communication in a WDM Network,” Int. J. Sci. Eng., vol. 6, no. 8, pp. 12701275, 2015.

[12] S. Kumar, P. A. K. Jaiswal, E. M. Kumar, E. R. Saxena, M. T. Student, and S. Shiats, "Performance Analysis of Dispersion Compensation in Long Haul Optical Fiber with DCF," IOSR J. Electron. Commun. Eng., vol. 6, no. 6, pp. 19-23, 2013.

[13] Gurpreet, Navdeep, and Ranvir, "Use_of_Dispersion_Compensating_Fiber_in," Int. J. Adv. Eng. Res. Sci., vol. 1, no. 4, 2014.

[14] U. Jadon, H. Nain, and V. Mishra, "NRZ VS RZ: Performance Analysis of SMF with Different Laser Sources at 10 Gbps," IEEE Int. Conf. Recent Trends Electron. Inf. Commun. Technol., pp. 43-46, 2016.

[15] S. Gupta and N. K. Shukla, "Pre- , Post , Symmetric1 and 2 Compensation Techniques with RZ Modulation,” Int. Conf. Recent Adv. Inf. Technol., 2012.

[16] F. E. Seraji and M. S. Kiaee, "Eye-Diagram-Based Evaluation of RZ and NRZ Modulation Methods in a 10 Gb / s Single-Channel and a 160 - Gb / s WDM Optical Networks,"vol. 7, no. 2, pp. 31-36, 2017.

[17] Z. Ibrahim, C. B. M. Rashidi, S. A. Aljunid, A. K. Rahman, and M. S. Anuar, "NRZ and RZ Analysis for Optical CDMA based on Radio over Fiber ( RoF ) Technique," 3rd Int. Conf. Electron. Des., pp. 151-154, 2016. 